\title{
Prognostic performance of inflammation-based prognostic indices in locally advanced non-small-lung cancer treated with Endostar and concurrent chemoradiotherapy
}

\author{
HUARONG TANG ${ }^{1}$, HONGLIAN MA ${ }^{1}$, FANG PENG $^{2}$, YONG BAO $^{2}$, \\ XIAO HU ${ }^{1}$, JIN WANG ${ }^{1}$, YUJIN XU ${ }^{1}$ and MING CHEN ${ }^{1}$ \\ ${ }^{1}$ Department of Radiation Therapy, Zhejiang Key Laboratory of Radiation Oncology, Zhejiang Cancer Hospital, \\ Hangzhou, Zhejiang 310022; ${ }^{2}$ Department of Radiation Oncology, Sun Yat-Sen University Cancer Center, \\ State Key Laboratory of Oncology in South China, Collaborative Innovation Center of Cancer Medicine, \\ Guangzhou, Guangdong 510275, P.R. China
}

Received October 12, 2015; Accepted February 9, 2016

DOI: $10.3892 / \mathrm{mco} .2016 .796$

\begin{abstract}
A proportion of patients with locally advanced nonsmall-celllung cancer(NSCLC) may benefitfromanti-angiogenic therapy combined with concurrent chemoradiotherapy; however, effective prognostic biomarkers are required for prognosis. In this study, we aimed to establish whether inflammation-based factors offer a prognostic benefit in terms of response rate (RR) and overall survival (OS) in stage III NSCLC patients treated by Endostar with concurrent chemoradiotherapy (CCRT). We retrospectively investigated an unselected cohort of stage III NSCLC patients, who were treated by combined Endostar and CCRT. The log-rank test was used to analyze the association between each clinical variable and OS. Cox regression models were fitted to identify risk factors associated with OS. A total of 82 patients with stage III NSCLC were treated with a combination of Endostar and CCRT and 78 patients were included in the data analysis. A total of 13 patients achieved a complete response, 49 achieved a partial response, 6 had stable disease, 8 had progressive disease and 2 patients could not be evaluated. The median progression-free survival of the entire group was 10.50 months (95\% CI: 6.298-14.702), while the median OS was 22.83 months (95\% CI: 19.156-26.504). On $\chi^{2}$ test analysis, the neutrophil-to-lymphocyte ratio (NLR) exerted a significant effect on RR ( $\mathrm{P}=0.048)$. The univariate analysis identified the factors associated with OS, including NLR $(\mathrm{P}=0.004)$ and monocyte count $(\mathrm{P}=0.001)$, whereas the multivariate analysis confirmed NLR $[\mathrm{P}=0.043$, hazard ratio $(\mathrm{HR})=0.502]$ and
\end{abstract}

Correspondence to: Dr Ming Chen, Department of Radiation Therapy, Zhejiang Key Laboratory of Radiation Oncology, Zhejiang Cancer Hospital, 38 Guangjiqiao Road, Hangzhou, Zhejiang 310022, P.R. China

E-mail: chenming@zjcc.org.cn

Key words: neutrophil-to-lymphocyte ratio, monocyte number, Endostar, non-small-cell lung cancer, concurrent chemoradiotherapy monocyte count $(\mathrm{P}=0.011, \mathrm{HR}=0.387)$ as independent prognostic factors for OS. Our results indicated that, in patients with stage III NSCLC treated by a combination of Endostar and CCRT, pre-treatment elevated NLR and monocyte number are negatively associated with OS.

\section{Introduction}

Lung cancer is the most common type of cancer worldwide (1). Concurrent chemoradiotherapy (CCRT) is the standard treatment strategy for locally advanced non-resectable non-small-cell lung cancer (NSCLC) (2). However, the clinical outcome is disappointing, with a 5-year survival rate of only $\sim 20 \%$ (range, $15-40 \%$ ) $(3,4)$. Recently, combined treatment with anti-angiogenic therapy and chemotherapy or radiotherapy has shown a survival advantage (5). Among all anti-angiogenic drugs, recombinant human endostatin (Endostar), when administered with traditional CRT in patients with locally advanced NSCLC, showed promising results (6-10). We previously conducted a phase II clinical trial of endostatin combined with CCRT in patients with locally advanced NSCLC, achieving improved local control and survival rate (11). However, previous research has demonstrated that not all patients benefit from anti-angiogenic therapy (11). Thus, suitable case selection for Endostar treatment is crucial to avoid excessive medical treatment.

It has been demonstrated that inflammation-mediated interaction between endothelial cells and the innate immune system plays an important role in resistance to anti-angiogenic therapy $(12,13)$. Neutrophil-to-lymphocyte ratio (NLR), as estimated by the number of neutrophils/lymphocytes in the peripheral blood, is a hallmark of systemic inflammation. It was found that, in sunitinib-treated metastatic renal cell carcinoma patients, NLR was associated with response rate (RR), progression-free survival (PFS) and overall survival (OS) (14). Furthermore, previously published studies indicate that inflammatory markers in bevacizumab-treated NSCLC patients may be used as prognostic indicator (15). However, no reports have been published regarding the prognostic value of 
inflammation-based factors in Endostar-based first-line treatment in locally advanced NSCLC.

Therefore, a retrospective analysis was conducted on the basis of clinical trials (recombinant human endostatin in combination with CCRT in patients with stage III NSCLC), to determine the association of NLR with RR, PFS and OS in patients treated with Endostar plus CCRT for locally advanced NSCLC.

\section{Patients and methods}

Patients and therapy. Between 2009/03/11 and 2015/06/10, 82 patients with untreated pathologically confirmed inoperable stage IIIA or IIIB NSCLC were enrolled in this study. The patients received a combined Endostar and CCRT regimen at the Sun Yat-Sen University Cancer Center and the Zhejiang Cancer Hospital. Endostar (Simcere Pharmaceutical, Nanjing, China) was administered according to the protocol of the clinical trials (11). Each patient received four cycles of Endostar, with each cycle lasting for 1 week. The patients received an intravenous (i.v.) loading dose of Endostar $\left(7.5 \mathrm{mg} / \mathrm{m}^{2} /\right.$ day) over $4 \mathrm{~h}$ for 7 days, or the same dose continuously pumped for $120 \mathrm{~h}$ on weeks 1, 3, 5 and 7. Endostar was administered 1 week prior to the administration of chemotherapy and thoracic radiotherapy, during the concurrent part of the treatment. Patients received two cycles of platinum-based chemotherapy with concurrent thoracic three-dimensional conformal radiation or intensity-modulated radiotherapy at 60-66 Gy in 30-33 fractions for 6-7 weeks. For chemotherapy, docetaxel $\left(65 \mathrm{mg} / \mathrm{m}^{2}\right)$ and cisplatin $\left(65 \mathrm{mg} / \mathrm{m}^{2}\right)$ on days 8 and 36 (TP regimen), or etoposide $\left(50 \mathrm{mg} / \mathrm{m}^{2}\right)$ on days $1-5$ and 29-33 and ciplatin $\left(50 \mathrm{mg} / \mathrm{m}^{2}\right)$ on days $1,8,29$ and 36 (EP regimen) were used. Peripheral blood samples were collected at baseline, prior to any treatment initiation. Of the 82 patients, 4 did not complete treatment; thus, a total of 78 cases qualified for analysis. Data were extracted from patient medical records. The data collected for our analysis included age, gender, pathological type, performance status (PS), pre-treatment laboratory findings (in particular neutrophil, lymphocyte, monocyte and platelet counts), and treatment outcome in terms of RR, PFS and OS. The responses were assessed according to Response Evaluation Criteria in Solid Tumors, version 1.1 (16). The study was performed according to bioethics standards of the participating institutions and the patients provided written informed consent to data management at trial enrollment.

Statistical analysis. A total of 78 patients were evaluated for OS and PFS. OS was defined as the time from the initiation of Endostar treatment to death, while PFS was defined as the time from the initiation of Endostar to disease progression or death. OS and PFS were considered as the primary endpoints. All potential prognostic factors were transformed into categorical variables. The patients were grouped as male vs. female, squamous vs. non-squamous cell carcinoma, neutrophil count $>7,000$ vs. $\leq 7,000 / \mathrm{mm}^{3}$ (upper limit of normal), lymphocyte count $\geq 1,100$ vs. $<1,100 / \mathrm{mm}^{3}$ (lower limit of normal), monocyte count $>600$ vs. $\leq 600 / \mathrm{mm}^{3}$ (upper limit of normal), platelet count $>350 \times 10^{3}$ vs. $\leq 350 \times 10^{3} / \mathrm{mm}^{3}$ (upper limit of normal), NLR $<5$ vs. $\geq 5$ (ratio between neutrophil and

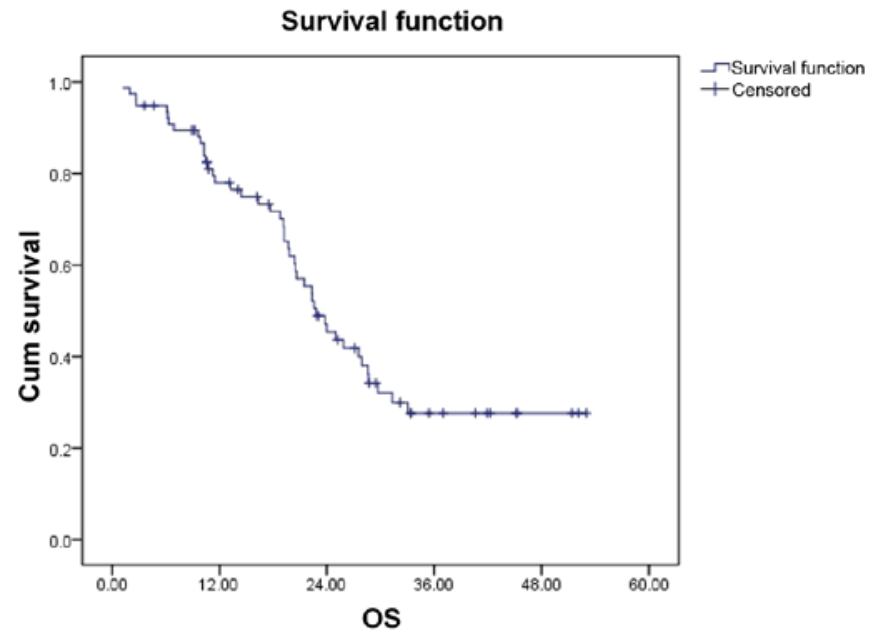

Figure 1. Overall survival (OS) curves for all patients. The median OS was 22.83 months.

lymphocyte counts at baseline) and platelet-to-lymphocyte ratio (PLR) $<300$ vs. $\geq 300$ (ratio between platelet and lymphocyte counts at baseline). The cut-off values of PLR and NLR were determined as previously described (17). Survival curves and medians were estimated with the Kaplan-Meier method and the association between each variable and survival was assessed by the log-rank test in the univariate analysis. The Cox proportional hazards model was used subsequently in the multivariate analysis to assess the contribution of each potential prognostic factor to survival. The most significant variables were entered in the model through a stepwise method. Two-category comparisons were performed with the $\chi^{2}$ test. The analysis was performed using the SPSS statistical package, version 16.0 (SPSS Inc., Chicago, IL, USA).

\section{Results}

Patient characteristics. The patients' characteristics at baseline are summarized in Table I. A total of 78 patients who received treatment with combined Endostar and CCRT were analyzed in our study, including 64 men and 14 women, with a median age of 57 years (range, 31-71 years). A total of 25 patients had stage IIIA and 53 patients stage IIIB disease; 25 patients had a performance status (PS) of 0 and 53 patients had a PS of $\geq 1$. As regards pathological type, 47 patients had squamous cell carcinoma and 31 patients non-squamous cell carcinoma. We observed complete response (CR) after treatment in 13 patients, partial response (PR) in 49 patients, stable disease (SD) in 6 patients and progressive disease (PD) in 8 patients, whereas 2 patients could not be evaluated. An NLR of $\geq 5$ was found in 23 patients $(29.48 \%)$, while only 7 patients $(8.97 \%)$ had a PLR of $\geq 300$. The RR in the NLR $<5.0$ group was significantly higher compared with that in the NLR $\geq 5$ group (87.27 vs. $60.87 \%$, respectively; $\mathrm{P}=0.048)$.

Inflammation-based indices and survival. The median follow-up time was 21.48 months (range, 0.20-52.97 months). The overall median PFS of the entire group was 10.50 months (95\% CI: 6.298-14.702), while the median OS was 22.83 months (95\% CI:19.156-26.504) (Fig. 1). 
Table I. Baseline characteristics of the patients $(n=78)$.

\begin{tabular}{lc}
\hline Characteristics & Values \\
\hline Age, years [median (range)] & $57(31-71)$ \\
Gender (male/female) & $64 / 14$ \\
PS $(0 / 1 / 2)$ & $25 / 52 / 1$ \\
Histology (Sq/non-Sq) & $47 / 31$ \\
Stage (IIIA/IIIB) & $25 / 53$ \\
Neutrophil count $\left(\right.$ mean $\left.\pm \mathrm{SD} / \mathrm{mm}^{3}\right)$ & $6,453 \pm 3,394(1,200-2,000)$ \\
Lymphocyte count $\left(\mathrm{mean} \pm \mathrm{SD} / \mathrm{mm}^{3}\right)$ & $1,454 \pm 585(260-3,380)$ \\
Monocyte count $\left(\mathrm{mean} \pm \mathrm{SD} / \mathrm{mm}^{3}\right)$ & $541 \pm 295(100-1,820)$ \\
Platelet count $\left(\mathrm{mean} \times 10^{3} \pm \mathrm{SD} / \mathrm{mm}^{3}\right)$ & $267 \pm 92(111-534)$ \\
NLR $(\geq 5.0 /<5.0)$ & $23 / 55$ \\
PLR $(\geq 300 /<300)$ & $7 / 71$
\end{tabular}

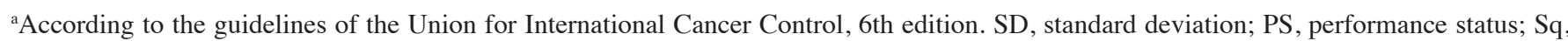
squamous cell carcinoma; NLR, neutrophil-to-lymphocyte ratio; PLR, platelet-to-lymphocyte ratio.

We analyzed the effect of potential clinical prognostic variables (including age, gender, PS, histology, stage, neutrophil count, lymphocyte count, monocyte count, platelet count and NLR) on OS (Table II). In the univariate analysis, NLR and monocyte count were found to be of significant prognostic value $(\mathrm{P}=0.004$ and $\mathrm{P}=0.001$, respectively). The $\mathrm{OS}$ of the NLR $\geq 5.0$ and the NLR $<5.0$ groups was $19.23 \pm 3.563$ months (95\% CI: 12.246-26.214) and 27.93 \pm 2.654 months (95\% CI: 22.727-33.133). In patients with a monocyte count $>600 / \mathrm{mm}^{3}$ and those with a monocyte count $\leq 600 / \mathrm{mm}^{3}$, the OS was $11.3 \pm 6.166$ months (95\% CI: $0.000-23.386)$ and 25.87 \pm 2.50 months (95\% CI: 20.97-30.77) (Fig. 2). Other factors, including age $(\mathrm{P}=0.712)$, gender $(\mathrm{P}=0.804), \mathrm{PS}$ $(\mathrm{P}=0.492)$, stage $(\mathrm{P}=0.498)$, histology $(\mathrm{P}=0.955)$, neutrophil count $(\mathrm{P}=0.157)$, lymphocyte count $(\mathrm{P}=0.867)$, platelet count $(\mathrm{P}=0.990)$ and PLR $(\mathrm{P}=0.962)$, exerted no significant effect on OS. The multivariate analysis confirmed NLR $(\mathrm{P}=0.043$, $\mathrm{HR}=0.502)$ and monocyte count $(\mathrm{P}=0.011, \mathrm{HR}=0.387)$ as independent risk factors predicting patient mortality. As regards $\mathrm{T}$ and $\mathrm{N}$ stage, the patient sample was too small to perform a statistical analysis (data not shown). In addition, NLR also exerted a significant effect on PFS $(\mathrm{P}<0.001)$, with a PFS of $6.17 \pm 1.23$ months $(95 \% \mathrm{Cl}: 3.76-858)$ and $13.27 \pm 2.113$ months (95\% Cl:9.129-17.411) in the NLR $\geq 5.0$ and NLR $<5.0$ groups, respectively.

\section{Discussion}

In the present study, we analyzed the potential correlation between clinical variables and clinical outcome in patients with locally advanced NSCLC treated with combined first-line therapy with the anti-angiogenic drug Endostar and CCRT. A total of 82 patients with locally advanced NSCLC were enrolled in the study; 4 patients did not complete treatment and, finally, 78 patients qualified for data analysis. The median PFS of the entire group was 10.50 months, while the median OS was 22.83 months. A total of 13 patients achieved CR after treatment, 49 achieved PR, 6 had SD, 8 developed PD, and 2 patients could not be evaluated. On $\chi^{2}$ test analysis, NLR
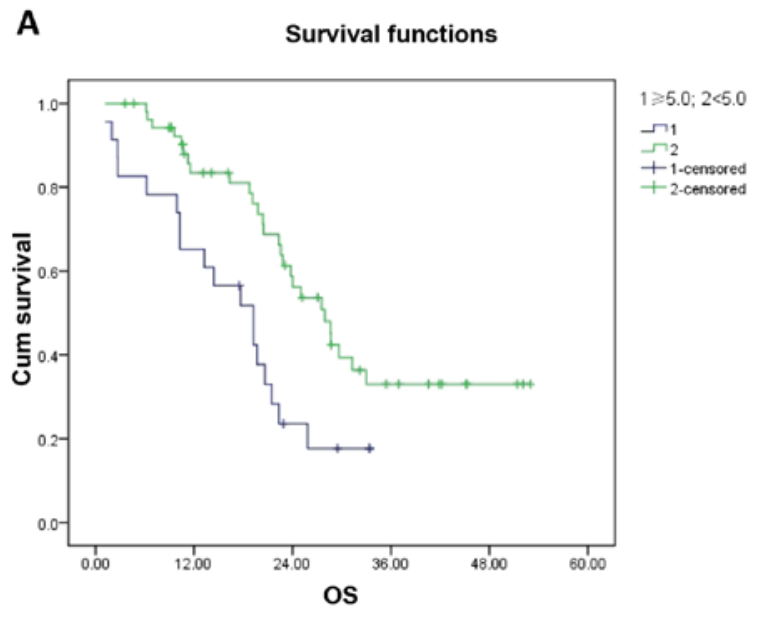

B

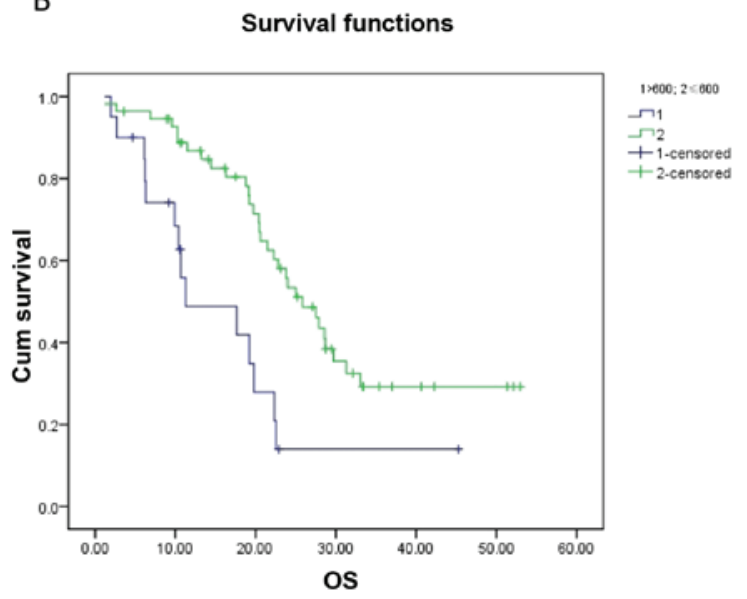

Figure 2. Correlation of overall survival (OS) with (A) neutrophil-to-lymphocyte ratio $(\mathrm{P}=0.004)$ and $(\mathrm{B})$ monocyte number $(\mathrm{P}=0.001)$ were analyzed by Kaplan-Meier curves.

exerted a significant effect on $\mathrm{RR}(\mathrm{P}=0.048)$. The univariate analysis revealed a correlation of low NLR and low monocyte count with longer OS. The multivariate analysis confirmed NLR and monocyte count as independent prognostic factors 
Table II. Univariate analysis associated for OS.

\begin{tabular}{|c|c|c|c|}
\hline Variables & OS (months) & $95 \% \mathrm{CI}$ & P-value \\
\hline Age, years & & & 0.712 \\
\hline$<65$ & $22.57 \pm 2.53$ & $17.612-27.528$ & \\
\hline$\geq 65$ & $23.83 \pm 2.829$ & $18.285-29.375$ & \\
\hline Gender & & & 0.804 \\
\hline Male & $22.83 \pm 2.159$ & $18.598-27.062$ & \\
\hline Female & $25.00 \pm 2.690$ & $19.727-30.273$ & \\
\hline PS & & & 0.492 \\
\hline 0 & $27.53 \pm 3.768$ & $20.145-34.915$ & \\
\hline$\geq 1$ & $20.50 \pm 1.770$ & $17.030-23.970$ & \\
\hline Histology & & & 0.955 \\
\hline $\mathrm{Sq}$ & $22.57 \pm 2.308$ & $18.046-27.094$ & \\
\hline Non-Sq & $22.30 \pm 1.306$ & $19.741-24.895$ & \\
\hline Stage & & & 0.498 \\
\hline IIIA & $25.87 \pm 8.203$ & 9.791-41.949 & \\
\hline IIIB & $22.57 \pm 1.472$ & $19.684-25.456$ & \\
\hline Neutrophil count, $/ \mathrm{mm}^{3}$ & & & 0.157 \\
\hline$\leq 7,000$ & $24.00 \pm 3.438$ & $17.261-30.739$ & \\
\hline$>7,000$ & $20.63 \pm 4.579$ & $11.655-29.605$ & \\
\hline Lymphocyte count, $/ \mathrm{mm}^{3}$ & & & 0.867 \\
\hline$<1,100$ & $22.330 \pm 1.575$ & $19.243-25.417$ & \\
\hline$\geq 1,100$ & $23.83 \pm 2.144$ & $19.628-28.032$ & \\
\hline Monocyte count, $/ \mathrm{mm}^{3}$ & & & 0.001 \\
\hline$\leq 600$ cells & $25.87 \pm 2.50$ & 20.97-30.77 & \\
\hline$>600$ cells & $11.30 \pm 6.166$ & $0.000-23.386$ & \\
\hline Platelet count, $/ \mathrm{mm}^{3}$ & & & 0.990 \\
\hline$\leq 350 \times 10^{3}$ & $23.830 \pm 3.287$ & $17.384-30.273$ & \\
\hline$>350 \times 10^{3}$ & $22.33 \pm 2.082$ & $18.249-26.411$ & \\
\hline NLR & & & 0.004 \\
\hline$<5.0$ & $27.93 \pm 2.654$ & $22.727-33.133$ & \\
\hline$\geq 5.0$ & $19.23 \pm 3.563$ & $12.246-26.214$ & \\
\hline PLR & & & 0.962 \\
\hline$\geq 300$ & $19.70 \pm 1.898$ & $15.979-23.421$ & \\
\hline$<300$ & $22.57 \pm 2.152$ & $18.352-26.788$ & \\
\hline
\end{tabular}

Values are presented as mean \pm standard deviation. OS, overall survival; CI, confidence interval; PS, performance score; Sq, squamous cell carcinoma; NLR, neutrophil-to-lymphocyte ratio; PLR, platelet-to-lymphocyte ratio.

predicting patient mortality. Keizman et al reported a correlation between low NLR and higher PFS, OS and RR in sunitinib treatment of metastatic renal cell carcinoma (14). In addition, Botta et al also found that a systemic inflammatory status at baseline is an important prognostic factor for PFS and OS in bevacizumab-treated patients with advanced NSCLC (15). These results all suggest that systemic inflammation is correlated with resistance to anti-angiogenesis.

Mononuclear cells differentiate into tumor-associated macrophages (TAMs) in the tumor tissue. Under certain conditions, TAMs undergo tumor-promoting M2-like macrophage polarization, and secrete angiogenic factors, such as vascular endothelial growth factor, interleukin- 8 and fibroblast growth factor, to induce vascular formation, thus promoting angiogenesis $(18,19)$.

A high level of NLR has been previously reported to be associated with prognosis in various tumor types, including renal cell carcinoma, malignant mesothelioma, colorectal liver metastases, advanced pancreatic cancer, ovarian cancer and gastric cancer (20-26). Previously published studies reported the prognostic value of pretreatment NLR in NSCLC patients (27-30), although other studies reported negative results (31-33). The opposite conclusions may have resulted from the variability of the investigated cases. Thus, although our study demonstrated that NLR is a prognostic factor in stage III NSCLC patients treated with Endostar combined 
with CCRT, this conclusion requires validation by further clinical studies.

The association between NLR and clinical outcome is complex and remains to be elucidated. NLR reflects systemic inflammation status to a certain extent. A high NLR reflects an increased neutrophil-dependent inflammatory response and a reduced lymphocyte-mediated antitumor immune response reaction, in turn leading to enhanced tumor invasiveness, thus resulting in tumor progression and poor prognosis (12). Anti-angiogenic therapy results in vascular normalization, but increased local hypoxia recruits bone marrow-derived cells, including dendritic cells, endothelial cells and pericyte progenitor cells and TAMs. These cells may produce a number of different angiogenic factors, and acquire drug resistance by hypoxic environment adaptation $(34,35)$.

The findings of this study should be interpreted with caution. First, this retrospective analysis did not investigate other indices of inflammation, such as C-reactive protein, erythrocyte sedimentation rate, or plasma inflammatory cytokines. These indicators are not conventional items for clinical detection and, therefore, their effect on treatment cannot be evaluated. In addition, considering patient diversity and sample size, we did not identify other statistically significant clinicopathological factors. Finally, neutrophil and lymphocyte count may also be affected by inflammation and drugs; however, these factors were not taken into account.

Despite these considerations, we consider high pretreatment NLR and monocyte count as indicators that patients with locally advanced NSCLC may benefit less from combined therapy with Endostar and CCRT. These markers may provide useful information for treatment decision-making, patient selection and the design of clinical trials. However, our results require validation by further prospective studies.

\section{Acknowledgements}

We would like to thank Dr Yan Xu for the collection of clinical data.

\section{References}

1. Siegel RL, Miller KD and Jemal A: Cancer statistics, 2015. CA Cancer J Clin 65: 5-29, 2015.

2. Pfister DG, Johnson DH, Azzoli CG, Sause W, Smith TJ, Baker S Jr, Olak J, Stover D, Strawn JR, Turrisi AT, et al: American Society of Clinical Oncology treatment of unresectable non-small-cell lung cancer guideline: Update 2003. J Clin Oncol 22: 330-353, 2004.

3. Rengan R, Maity AM, Stevenson JP and Hahn SM: New strategies in non-small cell lung cancer: Improving outcomes in chemoradiotherapy for locally advanced disease. Clin Cancer Res 17: 4192-4199, 2011.

4. Curran WJ Jr, Paulus R, Langer CJ, Komaki R, Lee JS, Hauser S, Movsas B, Wasserman T, Rosenthal SA, Gore E, et al: Sequential vs. concurrent chemoradiation for stage III non-small cell lung cancer: Randomized phase III trial RTOG 9410. J Natl Cancer Inst 103: 1452-1460, 2011.

5. Sandler A, Gray R, Perry MC, Brahmer J, Schiller JH, Dowlati A, Lilenbaum R and Johnson DH: Paclitaxel-carboplatin alone or with bevacizumab for non-small-cell lung cancer. N Engl J Med 355: 2542-2550, 2006

6. Han B, Xiu Q, Wang H, Shen J, Gu A, Luo Y, Bai C, Guo S, Liu W, Zhuang Z, et al: A multicenter, randomized, double-blind, placebo-controlled study to evaluate the efficacy of paclitaxel-carboplatin alone or with Endostar for advanced non-small cell lung cancer. J Thorac Oncol 6: 1104-1109, 2011.
7. $\mathrm{Mu} \mathrm{H}$, Shen $\mathrm{C}$ and Feng Y: Clinical observation on the target therapy of rh-endostatin, combined with chemotherapy in advanced non-small cell lung cancer. Chin J Lung Cancer 12: 780-784, 2009 (In Chinese).

8. Rong B, Yang S, Li W, Zhang W and Ming Z: Systematic review and meta-analysis of Endostar (rh-endostatin) combined with chemotherapy versus chemotherapy alone for treating advanced non-small cell lung cancer. World J Surg Oncol 10: 170, 2012.

9. Zhao X, Mei K, Cai X, Chen J, Yu J, Zhou C and Li Q: A randomized phase II study of recombinant human endostatin plus gemcitabine/cisplatin compared with gemcitabine/cisplatin alone as first-line therapy in advanced non-small-cell lung cancer. Invest New Drugs 30: 1144-1149, 2012.

10. Jiang XD, Dai P, Wu J, Song DA and Yu JM: Effect of recombinant human endostatin on radiosensitivity in patients with non-small-cell lung cancer. Int J Radiat Oncol Biol Phys 83: 1272-1277, 2012.

11. Bao Y, Peng F, Zhou QC, Yu ZH, Li JC, Cheng ZB, Chen L, Hu X, Chen YY, Wang J, et al: Phase II trial of recombinant human endostatin in combination with concurrent chemoradiotherapy in patients with stage III non-small-cell lung cancer. Radiother Oncol 114: 161-166, 2015.

12. Ribatti D, Crivellato E and Vacca A: Inflammation and antiangiogenesis in cancer. Curr Med Chem 19: 955-960, 2012.

13. Albini A, Tosetti F, Benelli R and Noonan DM: Tumor inflammatory angiogenesis and its chemoprevention. Cancer Res 65: 10637-10641, 2005.

14. Keizman D, Ish-Shalom M, Huang P, Eisenberger MA, Pili R, Hammers $\mathrm{H}$ and Carducci MA: The association of pre-treatment neutrophil to lymphocyte ratio with response rate, progression free survival and overall survival of patients treated with sunitinib for metastatic renal cell carcinoma. Eur J Cancer 48: 202-208, 2012.

15. Botta C, Barbieri V, Ciliberto D, Rossi A, Rocco D, Addeo R, Staropoli N, Pastina P, Marvaso G, Martellucci I, et al: Systemic inflammatory status at baseline predicts bevacizumab benefit in advanced non-small cell lung cancer patients. Cancer Biol Ther 14: 469-475, 2013.

16. Eisenhauer EA, Therasse P, Bogaerts J, Schwartz LH, Sargent D, Ford R, Dancey J, Arbuck S, Gwyther S, Mooney M, Rubinstein L, Shankar L, Dodd L, Kaplan R, Lacombe D and Verweij J: New response evaluation criteria in solid tumours: revised RECIST guideline (version 1.1). Eur J Cancer 45: 228-247, 2009.

17. Pinato DJ, Shiner RJ, Seckl MJ, Stebbing J, Sharma R and Mauri FA: Prognostic performance of inflammation-based prognostic indices in primary operable non-small cell lung cancer. $\mathrm{Br}$ J Cancer 110: 1930-1935, 2014.

18. Coffelt SB, Tal AO, Scholz A, De Palma M, Patel S, Urbich C, Biswas SK, Murdoch C, Plate KH, Reiss Y and Lewis CE: Angiopoietin-2 regulates gene expression in TIE2-expressing monocytes and augments their inherent proangiogenic functions. Cancer Res 70: 5270-5280, 2010.

19. Coffelt SB, Chen YY, Muthana M, Welford AF, Tal AO, Scholz A, Plate KH, Reiss Y, Murdoch C, De Palma M and Lewis CE: Angiopoietin 2 stimulates TIE2-expressing monocytes to suppress $\mathrm{T}$ cell activation and to promote regulatory $\mathrm{T}$ cell expansion. J Immunol 186: 4183-4190, 2011.

20. Kao SC,Pavlakis N, Harvie R, Vardy JL, Boyer MJ, van Zandwijk N and Clarke SJ: High blood neutrophil-to-lymphocyte ratio is an indicator of poor prognosis in malignant mesothelioma patients undergoing systemic therapy. Clin Cancer Res 16: 5805-5813, 2010

21. Kishi Y, Kopetz S, Chun YS, Palavecino M, Abdalla EK and Vauthey JN: Blood neutrophil-to-lymphocyte ratio predicts survival in patients with colorectal liver metastases treated with systemic chemotherapy. Ann Surg Oncol 16: 614-622, 2009.

22. Cho H, Hur HW, Kim SW, Kim SH, Kim JH, Kim YT and Lee K: Pre-treatment neutrophil to lymphocyte ratio is elevated in epithelial ovarian cancer and predicts survival after treatment. Cancer Immunol Immunother 58: 15-23, 2009.

23. Liao W, Zhang J, Zhu Q, Qin L, Yao W, Lei B, Shi W, Yuan S, Tahir SA, Jin J and He S: Preoperative neutrophil-to-lymphocyte ratio as a new prognostic marker in hepatocellular carcinoma after curative resection. Transl Oncol 7: 248-255, 2014.

24. An X, Ding PR, Li YH, Wang FH, Shi YX, Wang ZQ, He YJ, $\mathrm{Xu} \mathrm{RH}$ and Jiang WQ: Elevated neutrophil to lymphocyte ratio predicts survival in advanced pancreatic cancer. Biomarkerss 15: 516-522, 2010.

25. Yamanaka T, Matsumoto S, Teramukai S, Ishiwata R, Nagai Y and Fukushima M: The baseline ratio of neutrophils to lymphocytes is associated with patient prognosis in advanced gastric cancer. Oncology 73: 215-220, 2007. 
26. Ohno Y, Nakashima J, Ohori M, Hatano T and Tachibana M Pretreatment neutrophil-to-lymphocyte ratio as an independent predictor of recurrence in patients with nonmetastatic renal cell carcinoma. J Urol 184: 873-878, 2010.

27. Yao Y, Yuan D, Liu H, Gu X and Song Y: Pretreatment neutrophil to lymphocyte ratio is associated with response to therapy and prognosis of advanced non-small cell lung cancer patients treated with first-line platinum-based chemotherapy. Cancer Immuno Immunother 62: 471-479, 2013.

28. Cedrés S, Torrejon D, Martínez A, Martinez P, Navarro A, Zamora E, Mulet-Margalef $\mathrm{N}$ and Felip E: Neutrophil to lymphocyte ratio (NLR) as an indicator of poor prognosis in stage IV non-small cell lung cancer. Clin Transl Oncol 14: 864-869, 2012.

29. Sarraf KM, Belcher E, Raevsky E, Nicholson AG, Goldstraw P and Lim E: Neutrophil/lymphocyte ratio and its association with survival after complete resection in non-small cell lung cancer. J Thorac Cardiovasc Surg 137: 425-428, 2009.

30. Unal D, Eroglu C, Kurtul N, Oguz A and Tasdemir A: Are neutrophil/lymphocyte and platelet/lymphocyte rates in patients with non-small cell lung cancer associated with treatment response and prognosis? Asian Pac J Cancer Prev 14: 5237-5242, 2013.
31. Zhang J, Huang SH, Li H, Li Y, Chen XL, Zhang WQ, Chen HG and Gu LJ: Preoperative lymphocyte count is a favorable prognostic factor of disease-free survival in non-small-cell lung cancer. Med Oncol 30: 352, 2013.

32. Kobayashi N, Usui S, Kikuchi S, Goto Y, Sakai M, Onizuka M and Sato Y: Preoperative lymphocyte count is an independent prognostic factor in node-negative non-small cell lung cancer. Lung Cancer 75: 223-227, 2012.

33. Sakai T, Tsushima T, Kimura D, Hatanaka R, Yamada Y and Fukuda I: A clinical study of the prognostic factors for postoperative early recurrence in patients who underwent complete resection for pulmonary adenocarcinoma. Ann Thorac Cardiovasc Surg 17: 539-543, 2011

34. Erler JT, Bennewith KL, Cox TR, Lang G, Bird D, Koong A, Le QT and Giaccia AJ: Hypoxia-induced lysyl oxidase is a critical mediator of bone marrow cell recruitment to form the premetastatic niche. Cancer Cell 15: 35-44, 2009.

35. Yang L, DeBusk LM, Fukuda K, Fingleton B, Green-Jarvis B, Shyr Y, Matrisian LM, Carbone DP and Lin PC: Expansion of myeloid immune suppressor $\mathrm{Gr}^{+} \mathrm{CD} 11 \mathrm{~b}^{+}$cells in tumor-bearing host directly promotes tumor angiogenesis. Cancer Cell 6: 409-421, 2004. 